\title{
ДЕЙСТВИЕ РЕГУЛЯТОРОВ РОСТА НА ПЕРЕЗИМОВКУ СЕЯНЦЕВ СЛИВЫ УССУРИЙСКОЙ В УСЛОВИЯХ ПРИАНГАРЬЯ
}

\author{
A. A. Zarichnaya, O. S. Zatsepina
}

\section{THE EFFECT OF GROWTH REGULATORS FOR WINTERING OF USSURI PLUM SEEDLINGS IN THE CONDITIONS OF THE ANGARIA REGION}

Заричная Анна Александровна - асп. каф. ботаники, плодоводства и ландшафтной архитектуры Иркутского государственного аграрного университета им. А.А. Ежевского, Иркутская обл., Иркутский р-н., пос. Молодежный.

E-mail: anmi79@mail.ru

Зацепина Ольга Станиславовна - канд. биол. наук, доц. каф. ботаники, плодоводства и ландшафртной архитектуры Иркутского государственного аграрного университета им. А.А. Ежевского, Иркутская обл., Иркутский р-н., пос. Молодежный. E-mail: zippa@yandex.ru

Цель исследования - оценка пригодности регуляторов роста «Крезацин», «Эпин-Экстра», «Мивал-Агро» в качестве стимуляторов для повышения зимостойкости двухлетних растений сливы уссурийской в почвенноклиматических условиях Приангарья. Экспериментальные исследования были выполнены в 2009-2012 г2. путем проведения полевого опьта на территории питомника Учебного ботанического сада ФГБОУ ВО «Иркутский государственный университет» (БС ИГУ). Схема размещения растений на участках 0,9 × 0,2 м. В качестве биологических объектов исследованы однолетние сеянцы сливы уссурийской, в количестве 30 шт. по каждому препарату. Измерения высоты растений осуществлялись еженедельно с начала первой обработки регуляторами роста до конца периода вегетации. Замеры проводились с помощью рулетки от основания до верхушки. Приборная погрешность составляла 0,1 см. Внесение регуляторов роста внекорневое (7 обработок за сезон). В ходе экспериментальных исследований нами были выделены наиболее и наименее благоприятные сезонные периоды для перезимовки сеянцев сливы уссурийской. Условия зимы 2009/2010 2 г. были
Zarichnaya Anna Alexandrovna - Post-Graduate Student, Chair of Botany, Fruit Growing and Landscape Architecture, Irkutsk State Agrarian University named after A. A. Ezhevsky, Irkutsk Region, Irkutsk District, S. Molodyozhny.

E-mail: anmi79@mail.ru

Zatsepina Olga Stanislavovna - Cand. Biol. Sci., Assoc. Prof., Chair of Botany, Fruit Growing and Landscape Architecture, Irkutsk State Agrarian University named after A. A. Ezhevsky, Irkutsk Region, Irkutsk District, S. Molodyozhny.

E-mail: zippa@yandex.ru

крайне суровыми для перезимовки косточковых культур по сравнению со средними многолетними и последующими годами исследования. Представлены трехлетние результаты испытания влияния регуляторов роста на перезимовку двулетних сеянцев сливы уссурийской. Проведена статистическая обработка измерений показателей роста сливы уссурийской. В результате исследования проведена статистическая оценка высоты сеянцев сливы уссурийской по окончании перезимовки в зависимости от обработки фозиологически активными веществами (ФАВ) в течение вегетации. Установлено, что перезимовавшие растения, обработанные Крезацином, имели наименьший процент подмерзания надземной части (в 2010 2. - 80,6士2,1; в 2011 2. -

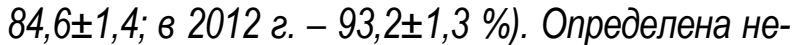
большая достоверная корреляция между cmeneнью повреждения растений после перезимовки и применением регуляторов роста в течение вегетации: $r b=0,4 \pm 0,9$ «Крезацин» и $r b=0,6 \pm 0,9$ «Мивал-Агро», т. е. чем меньше степень повреждения растения, тем выше стимулирующие свойства тестируемого вещества.

Ключевые слова: зимостойкость, перезимовка, однолетние и двухлетние сеянцы, слива 
уссурийская, фризиологически активнье вещества (ФАВ), регуляторы роста, корреляция.

The purpose of the study was to assess the suitability of growth regulators, such as "Krezacin", "Epin-Extra", "Mival-Agro" as the stimulants to increase the winter hardiness of biennial plants of Ussuri plum in soil and climatic conditions within the Angara Region. Pilot studies were performed in 2009-2012 by carrying out field experiment on the territory of the production nursery of the Educational Botanical Garden FSBEI HPE "Irkutsk State University" (BS ISU). The layout of plants in the plots was $0.9 \times 0.2 \mathrm{~m}$. As biological objects for the study annual seedlings of Ussuri plum were taken in the amount of 30 pieces for each stimulator. Plant height measurements were made from the base to the top weekly, from the beginning of the first treatment with growth regulators to the end of vegetation season. The instrumental error made $0.1 \mathrm{~cm}$. The introduction of growth regulators was extra root (7 treatments per a season). In the course of experimental studies the most and least favorable seasonal periods for overwintering Ussuri plum seedlings were identified. The winter conditions of 2009/2010 were extremely severe for overwintering drupaceous trees compared with the long-term and subsequent years of the study Three-years results of the test of the influence of growth regulators on rewintering of biennial seedlings of Ussuri plum were presented. Statistical processing of the measurements of growth indicators was carried out. As a result of the research statistical assessment of the height of seedlings of Ussuri plum upon termination of rewintering depending on processing by physiologically active agents (PAA) during vegetation was carried out. It was established that overwintered plants treated with Crezacin had had the lowest percentage of freezing of aerial parts (in $2010-80.6 \pm 2.1$; in $2011-84.6 \pm 1.4$; in $2012-93.2 \pm 1.3 \%$ ). A small reliable correlation was established between the degree of damage to plants after wintering and the using growth regulators during vegetation season: $r b=0.4 \pm 0.9$ ("Crezacin") and $r b=0.6 \pm 0.9$ ("Mival-Agro"), i. e. the lower the degree of damage to the plant, the higher were stimulating properties of the test substance.

Keywords: winter hardiness, wintering, annual and biennial seedlings, Ussuri plum, physiologically active agents (PAA), growth regulators, correlation.
Введение. Последовательность и продолжительность всех этапов развития растений следует по определенному ритму, которым управляет большое количество внутренних и внешних факторов. Согласно литературным данным [1], жизненный цикл роста и развития растений определяется соотношением в системе ауксин ингибитор. Одним из важнейших факторов эндогенной регуляции роста являются ростовые вещества. В растениеводстве ФАВ, ведущие к стимуляции или торможению отдельных ростовых процессов, нашли широкое применение [2].

В то же время ФАВ практически не применяются в период вегетации однолетних сеянцев древесных растений, где вопросы об успешности, жизнеспособности и сроках выращивания этих растений как будущего подвойного материала всегда являются важнейшими.

В связи с этим изучение механизма отзывчивости плодовых растений на воздействие физиологически активных и кальцийсодержащих препаратов требует всестороннего и глубокого изучения и является весьма актуальным [3].

Цель исследования: провести сравнительную оценку пригодности ФАВ, таких как «Крезацин», «Эпин-Экстра», «Мивал-Агро», в качестве стимуляторов для повышения зимостойкости однолетних растений сливы уссурийской в почвенно-климатических условиях Приангарья.

Для реализации цели были поставлены следующие задачи:

- испытать действие регуляторов роста как биологически активных веществ, способствующих вызреванию побегов [4];

- изучить влияние обработки однолетних сеянцев сливы уссурийской регуляторами роста на их перезимовку.

Материалы и методы исследования. Исследование проводилось на территории питомника БС ИГУ путем проведения полевого опыта в 2009-2012 гг. Питомник БС ИГУ расположен в черте г. Иркутска, на левобережной части р. Ангара на хорошо прогреваемом юго-западном склоне Кайской горы.

Почва на территории питомника среднесуглинистая светло-серая лесная со среднемощным гумусовым горизонтом мелкокомковатой структуры, содержащим 3,0-5,0 \% гумуса, нейтральной реакцией среды (pH - 5,6-6,0) [5]. 
Схема размещения растений на участке $0,9 \times$ 0,2 м. Для проведения исследования выбраны вещества и препараты, применяемые при возделывании полевых, плодово-ягодных и других культур как стимуляторы ростовых процессов широкого спектра действия:

- «Крезацин» - в концентрации 50 мг на 1 л воды с добавлением 1 мг дифенилмочевины, 0,3 г сульфата цинка и 0,15 мл терпенсила;

- «Эпин-экстра» - 0,4 мл на 10 л воды;

- «Мивал-агро» - 0,2 г на 10 л воды;

- хлористый кальций - 2 г на 1 л воды.

Модельными объектами исследования служили однолетние сеянцы сливы уссурийской в количестве 30 шт. по каждому препарату. Стимуляторы ежегодно применяли в виде внекорневого внесения (опрыскивания) в утренние и вечерние («Эпин-Экстра») часы по вегетирующим растениям в бездожную погоду. Обработку «Крезацином», «Эпин-экстра» и «Мивал-агро» проводили с середины июня до конца июля один раз в неделю (всего по 7 обработок). Хлористый кальций применялся один раз в неделю только в августе (всего 4 обработки).

Еженедельно, с начала первой обработки ФАВ до конца периода вегетации, производились измерения высоты от основания до вер- хушки растений с помощью рулетки. Приборная погрешность составляла $0,1 \mathrm{~cm}$.

Для оценки зимостойкости сеянцев использовали полевой метод испытаний [6], учет зимних повреждений проводили вскоре после распускания почек, степень повреждений оценивали по 6-балльной шкале.

Статистический анализ провели с помощью определения показателей количественной изменчивости и вычисления коэфффициента корреляции [7].

Результаты исследования и их обсуждение. В ходе экспериментальных исследований были выделены наиболее и наименее благоприятные сезонные периоды для перезимовки сеянцев сливы уссурийской.

Наименее благоприятным для перезимовки большинства изучаемых сеянцев сливы уссурийской был 2009/10 г. Он характеризовался коротким периодом закалки, поскольку все зимние месяцы отмечены продолжительными периодами, с температурой воздуха ниже минус $30{ }^{\circ} \mathrm{C}$, а также поздней и холодной весной [8]. Степень повреждения в 4 балла отмечены у контрольных (3,3 \%) и обработанных хлористым кальцием $(6,6 \%)$ сеянцев (рис. 1$)$.

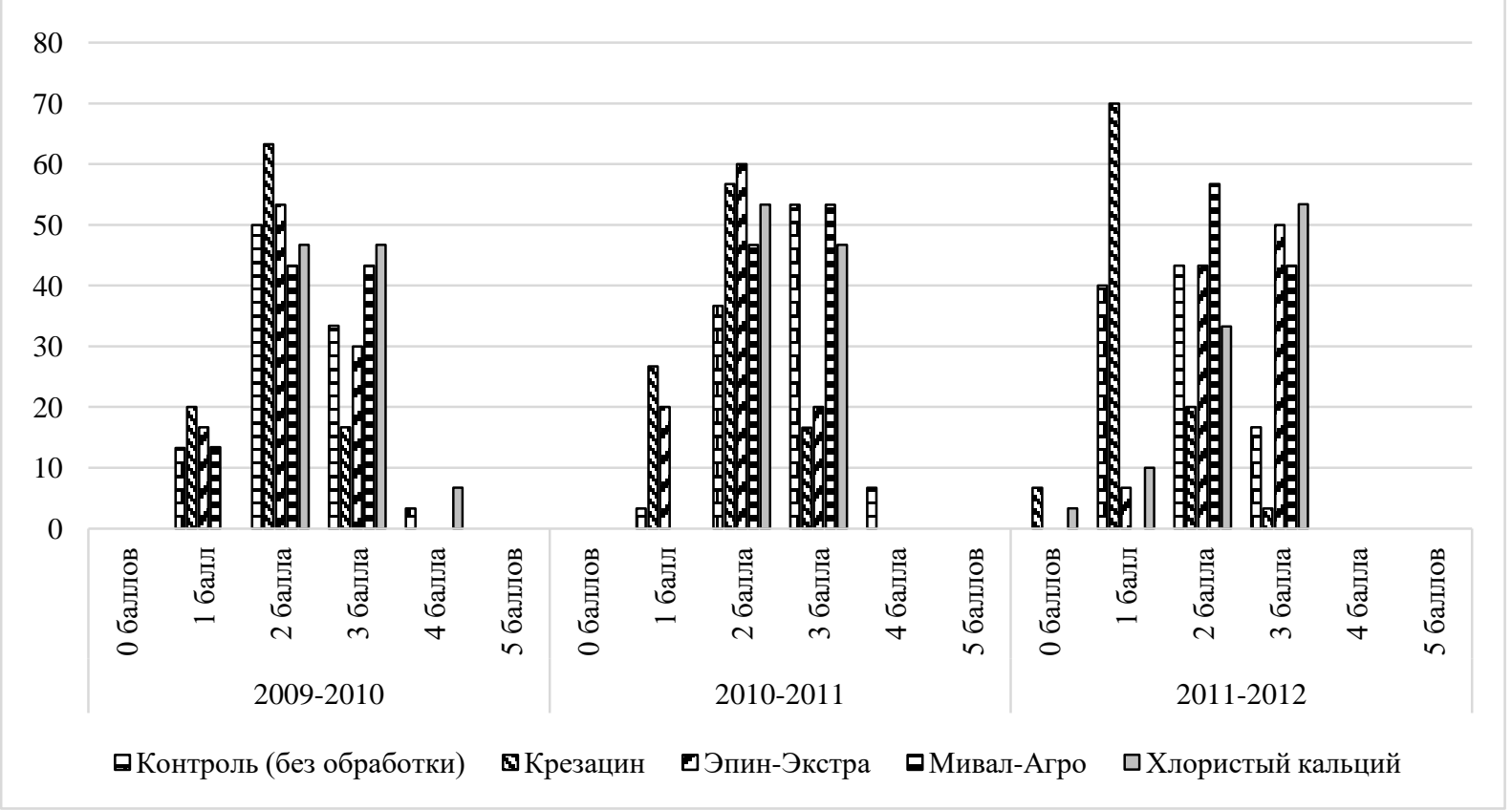

Puc. 1. Подмерзание надземной части двухлетних сеянцев сливы уссурийской после перезимовки с учетом степени повреждения, \% 
Погодные условия зимы 2010/11 г. оказались относительно благоприятными для перезимовки растений. Зима характеризовалась резко контрастными по температурному режиму периодами, поздним установлением снежного покрова. Прохладная со снегопадами погода первых двух декад марта задерживала начало интенсивного таяния снежного покрова. После перезимовки 2010/11 г. степень повреждения в 0 баллов не отмечена ни у одного растения сливы. Подмерзание надземной части у исследуемых растений, обработанных «Крезацином», по степени их повреждения в 1 балл составило 26,7 \%; «Эпин-экстра» - 20,0; контроль - 3,3 \%. Наибольший процент подмерзания в 3 балла отмечен у контрольных растений и обработанных «Мивал-Агро» - по 53,3 \%, а наименьший у обработанных «Крезацином» - 16,6 \%. Повреждения в 4 балла отмечены только у контрольных растений $-6,7$ \% (см. рис. 1).

Осень 2011 г. была самая продолжительная за предыдущие 10 лет. В первой половине сентября преобладала холодная дождливая погода, в остальные дни сентября-октября - теплая, сухая, солнечная. В октябре большую часть месяца преобладала аномально-теплая сухая солнечная погода. Зима 2011/12 г. отличалась частыми снегопадами, с периодами резких интенсивных потеплений и похолоданий. Весна 2012 г. началась рано, но была затяжной с преобладанием резко контрастной неустойчивой погоды с обильными осадками. После перезимовки 2011/12 г. отсутствовало подмерзание надземной части у растений, обработанных «Крезацином» - 6,7 \% и хлористым кальцием 3,3\%. Подмерзание надземной части у исследуемых растений по степени их повреждения в 1 балл составило 40,0% (контроль); 70,0 («Крезацин»); 6,7 («Эпин-экстра»); 3,3 («МивалАгро»); 10,0 \% (хлористый кальций). Наибольший процент подмерзания (2 балла) отмечен у растений, обработанных «Мивал-Агро» $56,7 \%$, а наименьший - у обработанных «Крезацином» - 20,0 \%. Подмерзание надземной части по степени их повреждения в 3 балла составило 16,7 \% (контроль); 3,3 («Крезацин»); 50,0 («Эпин-экстра»); 43,3 («Мивал-Агро»); 53,4 \% (хлористый кальций) (см. рис. 1).

Основные статистические показатели выборки, такие как среднее арифметическое М (высота растения после перезимовки, \%), среднее квадратическое отклонение $\sigma$, ошибка среднего арифметического mM, достоверность определения среднего по критерию Стьюдента $t$ факт., коэффициент вариации выборки ט, ошибка коэфффициента вариации mu, точность опыта $P$ приведены в таблице 1.

Средние величины линейных замеров высоты растения удовлетворительные во всех вариантах ( $P=1,4-3,6 \%)$. Перезимовавшие растения имеют нормальное варьирование по высоте и относятся ко второму баллу вариабельности (нормальное варьирование, $\mathrm{v}=7,4-19,6 \%$, т. е. меньше $24 \%$ ).

Полученные значения критерия Стьюдента значительно выше табличного, поэтому средние арифметические вполне достоверны.

Наибольший процент высоты отмечен у перезимовавших растений, обработанных «Крезацином», по всем трем годам учета (в 2010 г. $80,6 \pm 2,1$; в 2011 г. $-84,6 \pm 1,4$; в 2012 г. $93,2 \pm 1,3 \%)$.

Считается, что обработка растений ФАВ регулирует процесс вызревания побегов древесных растений и улучшает перезимовку этих растений [4]. На основании этого утверждения и проведенных нами полевых наблюдений была выдвинута гипотеза о связи признака зимостойкости с обработкой ФАВ в течение вегетации.

Для проверки этой гипотезы был вычислен бисериальный коэфффициент корреляции - между процентом подмерзания надземной части у исследуемых растений, обработанных ФАВ, и степенью их повреждения в баллах по сравнению с необработанными растениями (контрольными) в среднем за три года исследований (табл. 2). 
Статистические показатели перезимовки двухлетних сеянцев сливы уссурийской в зависимости от обработки регуляторами роста

\begin{tabular}{|c|c|c|c|c|c|c|c|c|c|}
\hline \multirow{2}{*}{$\begin{array}{c}\text { Год } \\
\text { учета }\end{array}$} & \multirow{2}{*}{$\begin{array}{c}\text { Вариант } \\
\text { исследования }\end{array}$} & \multirow[t]{2}{*}{$M, \%$} & \multirow[t]{2}{*}{$\sigma$} & \multirow[t]{2}{*}{$\mathrm{mM}$} & \multicolumn{2}{|c|}{$\begin{array}{c}\text { Критерий Стью- } \\
\text { дента }\end{array}$} & \multirow[t]{2}{*}{ U } & \multirow[t]{2}{*}{ mo } & \multirow[t]{2}{*}{$P$} \\
\hline & & & & & tфракт. & ттабл. & & & \\
\hline \multirow{6}{*}{2010} & Контроль & 77,9 & 11,4 & 2,1 & 37,1 & 2,05 & 14,6 & 1,9 & 2,7 \\
\hline & Крезацин & 80,6 & 11,7 & 2,1 & 38,4 & 2,05 & 14,5 & 1,9 & 2,6 \\
\hline & Эпин-Экстра & 78,3 & 10,9 & 2,0 & 39,2 & 2,05 & 13,9 & 1,8 & 2,6 \\
\hline & Мивал-Агро & 75,5 & 10,3 & 1,9 & 39,7 & 2,05 & 13,6 & 1,8 & 2,5 \\
\hline & Хлористый кальций & 72,1 & 14,1 & 2,6 & 27,7 & 2,05 & 19,6 & 2,6 & 3,6 \\
\hline & $\mathrm{HCP}_{05}$ & 5,9 & & & & & & & \\
\hline \multirow{6}{*}{2011} & Контроль & 72,0 & 9,9 & 1,8 & 40,0 & 2,05 & 13,8 & 1,8 & 2,5 \\
\hline & Крезацин & 84,6 & 7,6 & 1,4 & 60,4 & 2,05 & 9,0 & 1,2 & 1,7 \\
\hline & Эпин-Экстра & 81,8 & 8,9 & 1,6 & 51,1 & 2,05 & 10,9 & 1,4 & 2,0 \\
\hline & Мивал-Агро & 73,5 & 8,1 & 1,5 & 49,0 & 2,05 & 11,0 & 1,4 & 2,0 \\
\hline & Хлористый кальций & 75,7 & 10,5 & 1,9 & 39,8 & 2,05 & 13,9 & 1,8 & 2,5 \\
\hline & $\mathrm{HCP}_{05}$ & 4,8 & & & & & & & \\
\hline \multirow{6}{*}{2012} & Контроль & 84,8 & 10,5 & 1,9 & 44,6 & 2,05 & 12,4 & 1,6 & 2,2 \\
\hline & Крезацин & 93,2 & 6,9 & 1,3 & 71,7 & 2,05 & 7,4 & 1,0 & 1,4 \\
\hline & Эпин-Экстра & 75,0 & 10,3 & 1,9 & 39,5 & 2,05 & 13,7 & 1,8 & 2,5 \\
\hline & Мивал-Агро & 75,6 & 8,9 & 1,6 & 47,3 & 2,05 & 11,8 & 1,5 & 2,1 \\
\hline & Хлористый кальций & 74,3 & 11,8 & 2,1 & 35,4 & 2,05 & 15,9 & 2,1 & 2,8 \\
\hline & $\mathrm{HCP}_{05}$ & 5,1 & & & & & & & \\
\hline
\end{tabular}

\section{Коэффициент корреляции у перезимовавших двухлетних сеянцев сливы уссурийской, обработанных ФАВ в течение вегетации}

Таблица 2

\begin{tabular}{|l|c|c|c|}
\hline \multicolumn{1}{|c|}{ ФАВ } & $\begin{array}{c}\text { Еисериальный } \\
\text { Коэсрфициент } \\
\text { корреляции rb }\end{array}$ & $\begin{array}{c}\text { Ошибка бисериального } \\
\text { коэфрфициента корреляции } \\
\text { mrb }\end{array}$ & $\begin{array}{c}\text { Критерий } \\
\text { Стьюдента, } \\
\text { тфракт. }\end{array}$ \\
\hline Крезацин & 0,4 & 0,9 & 0,4 \\
\hline Эпин-Экстра & $-0,12$ & 0,9 & 0,12 \\
\hline Мивал-Агро & 0,6 & 0,9 & 0,6 \\
\hline Хлористый кальций & $-0,13$ & 0,9 & 0,13 \\
\hline
\end{tabular}

Проведенный статистический анализ экспериментальных данных показал несущественную корреляционную связь между степенью повреждения и исследуемыми регуляторами роста, поскольку вычисленное значение $t=0,13-0,4$ меньше табличного (ттабл = 1,96). Следовательно, обработка регуляторами роста слабо влияет на зимостойкость двухлетних сеянцев сливы уссурийской. 
Выводы. Исследование показало, что повреждаются как контрольные растения, так и обрабатываемые ФАВ. Установлено, что перезимовавшие растения, обработанные крезацином, имели наименьший процент подмерзания надземной части (в 2010 г. - 80,6 2,1; в 2011 г. $84,6 \pm 1,4$; в 2012 г. $-93,2 \pm 1,3 \%$ ).

Выявлена небольшая достоверная корреляция между степенью повреждения растений после перезимовки и применением регуляторов роста в течение вегетации: $r b=0,4 \pm 0,9$ («Крезацин») и rb=0,6 $\pm 0,9$ («Мивал-Агро»), т. е. чем меньше степень повреждения растения, тем выше стимулирующие свойства тестируемого вещества.

\section{Литература}

1. Кефрели В.И. Природные ингибиторы роста и фитогормоны. М.: Наука, 1974. 253 с.

2. Рункова Л.В. Действие регуляторов роста на декоративные растения. М.: Наука, 1985. $151 \mathrm{c}$

3. Митрохина А.А., Зацепина О.С., Раченко М.А. Оценка зимостойкости сеянцев косточковых культур в полевых и лабораторных условиях // Вестник ИрГСХА. 2014. Вып. 65. C. 21-29.

4. Косулина Л.Г., Луценко Э.К., Аксенова В.А. Физиология устойчивости к неблагоприятным факторам среды. Ростов н/Д., 2007. $236 \mathrm{c}$.

5. Кузеванов В.Я., Сизых С.В. Ресурсы Ботанического сада Иркутского госуниверситета: образовательные, научные и социально экологические аспекты. Иркутск, 2005. 243 с.

6. Тюрина М.М., Красова Н.Г., Резвякова С.Н. и др. Изучение зимостойкости сортов плодовых и ягодных растений в полевых и лабораторных условиях // Программа и методика сортоизучения плодовых, ягодных и орехоплодных культур. Орел: ВНИИСПК, 1999. C. 59-68.

7. Зайщев Г.Н. Математика в экспериментальной ботанике. М.: Наука, 1990. 296 с.

8. Научно-прикладной справочник по агрометеорологическим ресурсам России: агрометеорологический ежегодник Иркутской области за 2009-2010, 2010-2011, 2011-2012 сельскохозяйственные годы. Вып. № 22, 23, 24.

\section{Literatura}

1. Kefeli V.I. Prirodnye ingibitory rosta i fitogormony. M.: Nauka, 1974. $253 \mathrm{~s}$.

2. Runkova L.V. Dejstvie reguljatorov rosta na dekorativnye rastenija. M.: Nauka, 1985. $151 \mathrm{~s}$.

3. Mitrohina A.A., Zacepina O.S., Rachenko M.A. Ocenka zimostojkosti sejancev kostochko-vyh kul'tur v polevyh i laboratornyh uslovijah /I Vestnik IrGSHA. 2014. Vyp. 65. S. 21-29.

4. Kosulina L.G., Lucenko Je.K., Aksenova V.A. Fiziologija ustojchivosti $k$ neblagoprijatnym faktoram sredy. Rostov n/D., 2007. $236 \mathrm{~s}$.

5. Kuzevanov V.Ja., Sizyh S.V. Resursy Botanicheskogo sada Irkutskogo gosuniversiteta: obrazovatel'nye, nauchnye i social'no jekologicheskie aspekty. Irkutsk, 2005. $243 \mathrm{~s}$.

6. Tjurina M.M., Krasova N.G., Rezvjakova S.N. i dr. Izuchenie zimostojkosti sortov plodovyh i jagodnyh rastenij $\mathrm{v}$ polevyh i laboratornyh uslovijah // Programma i metodika sortoizuchenija plodovyh, jagodnyh i orehoplodnyh kul'tur. Orel: VNIISPK, 1999. S. 59-68.

7. Zajcev G.N. Matematika v jeksperimental'noj botanike. M.: Nauka, 1990. $296 \mathrm{~s}$.

8. Nauchno-prikladnoj spravochnik po agrometeorologicheskim resursam Rossii: agrometeorologicheskij ezhegodnik Irkutskoj oblasti za 2009-2010, 2010-2011, 2011-2012 sel'skohozjaj-stvennye gody. Vyp. № 22, 23, 24. 